\title{
ACESSIBILIDADE NAS BIBLIOTECAS ESCOLARES ESTADUAIS DE LONDRINA
}

\section{Ivonete Aparecida Andrade \\ Roma \\ Bacharel em Biblioteconomia pela Universidade Estadual de Londrina. E-mail: nete.roma@hotmail.com}

\section{Luciane de Fátima Beckman Cavalcante}

Doutora em Ciência da Informação pela Universidade Estadual Paulista Júlio de Mesquita Filho. Professora adjunta na Universidade Estadual de Londrina.

E-mail: lucifbc@gmail.com

\section{RESUMO}

Este estudo aborda a importância da acessibilidade nas bibliotecas escolares estaduais da cidade de Londrina, PR; apresenta as dificuldades existentes para a inclusão do usuário portador de necessidade especial, com o intuito de alertar gestores escolares quanto à conscientização de mudanças necessárias na biblioteca escolar; e enfoca a necessidade de se ter profissionais comprometidos com as bibliotecas escolares. A pesquisa teve como universo as bibliotecas escolares da cidade de Londrina, especificamente duas bibliotecas de cada região da cidade. A coleta de dados foi realizada por meio de um formulário específico de observação. A pesquisa apontou que as bibliotecas escolares pesquisadas atendem parcialmente aos quesitos de acessibilidade para pessoas com necessidades especiais, com enfoque nos cadeirantes e nas pessoas com mobilidade reduzida. Conclui-se que o respeito à legislação e às normas brasileiras "Acessibilidade a edificações, mobiliário, espaço e equipamentos urbanos" é fundamental para que as bibliotecas escolares sejam acessíveis para todas as pessoas.

Palavras-chave: Biblioteca Escolar. Acessibilidade. Profissionais que atuam em biblioteca escolar. Pessoas com Mobilidade Reduzida

\section{ABSTRACT}

This study addresses the importance of accessibility in state school libraries in the city of Londrina, PR; it presents the difficulties for the inclusion of the users with special needs, in order to alert school administrators of the changes needed in the school library. It focuses on the need to have professionals committed to the school libraries. The research had as its universe the school libraries in the city of Londrina, specifically two libraries in each region of the city. Data collection was conducted through a specific form of observation. The research pointed that the school libraries surveyed partially assist the requirements for people with special needs, focusing on the handicap and on people with reduced mobility. It concludes that compliance with legislation and standards in Brazil accessibility to the building, furniture equipment and urban space is fundamental to school libraries in order to become accessible to all people. 
Keywords: School library. Accessibility. Professionals that act at school library. People with Reduced Mobility

\section{INTRODUÇÃo}

A inadequação da estrutura predial das escolas da rede de ensino regular é uma das principais dificuldades identificadas para atender os alunos com deficiência, transtornos globais do desenvolvimento e altas habilidades ou superdotação. Na sua maioria, as escolas não são projetada para dar acessibilidade aos portadores de deficiência física. Nesse universo de ensino, destacam-se as bibliotecas escolares, cuja função é promover a sociabilidade e a democratização do conhecimento, pois o acesso à informação é um direito universal.

As pessoas portadoras de algum tipo de deficiência física sempre sofreram com o preconceito ou a limitação de acesso a vários ambientes, dentre eles, o escolar. Nesse cenário, o Ministério da Educação (MEC), por meio dos programas de escola acessível, tem lançado manuais, livros e resoluções para melhorar o acesso destes alunos nas escolas públicas. 0 decreto nำ 5.296/2004, artigo 24 diz que:

Os estabelecimentos de ensino de qualquer nível, etapa ou modalidade públicos ou privados, proporcionarão condições de acesso e utilização de todos os seus ambientes ou compartimentos para pessoas com deficiência ou mobilidade reduzida, inclusive salas de aula, bibliotecas, auditórios ginásios e instalações desportivas, laboratórios, áreas de lazer e sanitários (BRASIL, 2004).

Este Decreto faz com que a escola constantemente estude formas de inclusão educacional para os alunos com necessidades especiais. Através disso, é feito o reconhecimento de como atender às diferenças individuais de qualquer aluno que esteja dentro deste contexto e manter a responsabilidade de oferecer a manutenção adequada para o bom funcionamento da estrutura.

Diante disso, o Governo do Paraná, juntamente com o Ministério da Educação (MEC) e a Secretaria de Educação Continuada, Alfabetização, Diversidade e Inclusão (SECADI), tentam integrar os alunos especiais na rede de ensino comum, em vez de frequentarem uma escola que recebe somente alunos especiais, como, por exemplo, Associação de Pais e Amigos dos Excepcionais (APAE). 
Percebe-se, muitas vezes, a falta de capacitação para os profissionais que atuam nas bibliotecas dessas escolas, principalmente no que se refere ao procedimento e estratégia para a inclusão dos alunos portadores de deficiência física. Diante das barreiras expostas, fica visível a necessidade de analisar a acessibilidade nas bibliotecas escolares públicas, integrando os alunos com necessidades especiais de forma adequada. Nesse sentido, a problemática desta pesquisa centra-se na seguinte pergunta: as bibliotecas escolares de Londrina atendem aos requisitos de acessibilidade aos deficientes físicos?

Destaca-se que, dentre os elementos que justificam esta pesquisa, nos apoiamos na Constituição Federal, a qual determina que "todos têm direito a ter acesso à educação" e, no art. 205 (BRASIL, 1988), preconiza a "igualdade e condições para o acesso e permanência nas escolas". Porém, as escolas públicas enfrentam barreiras nas estruturas arquitetônicas construídas antes das leis que favorecem o acesso aos deficientes. Segundo Melo e Pupo (2010, p.13),

\begin{abstract}
A biblioteca escolar deve ser um espaço de apoio ao AEE (Atendimento Educacional Especializado), além de suas principais atribuições de organizar, preservar e disseminar a informação que vai gerar novos conhecimentos. Portanto, acessibilidade, em seus vários aspectos, é um requisito fundamental para seu funcionamento e atendimento aos alunos com qualidade.
\end{abstract}

Por meio desta reflexão, a pesquisa teve o intuito de abordar o assunto apresentado e elucidar a importância do acesso de alunos com deficiência física às instituições escolares. Eles devem ter acessibilidade nas bibliotecas escolares públicas para que suas potencialidades sejam desenvolvidas e para que possam ter, de fato, acesso à informação. Nesse sentido, observa-se a necessidade de que os profissionais, que atuam nesta área, vejam os alunos com deficiência física como usuários que necessitam da informação e do espaço adequado para sua inserção no ambiente da biblioteca.

Por fim, este trabalho justifica-se pela contribuição que dará como alerta e repercussão aos gestores escolares, de modo que as bibliotecas possam oferecer qualidade e acessibilidade aos alunos portadores de deficiência que a frequentam. 


\section{ACESSIBILIDADE}

Existe uma confusão quanto à utilização, na prática, dos conceitos de acessibilidade e acesso, que pode ser observada em determinados momentos e, por isso, são necessários esclarecimentos. A acessibilidade está relacionada à pessoa com necessidades especiais, quando esta consegue adentrar um espaço, movimentar-se dentro deste e utilizá-lo como qualquer outro indivíduo. 0 acesso é quando o indivíduo chega até o espaço, mas não consegue movimentar-se dentro dele. Pois, muitas vezes, os ambientes têm acesso, mas não têm acessibilidade. A Constituição Federal de 1988, em seu Capítulo VII, art. 227, prevê a

[...] facilitação do acesso aos bens e serviços coletivos, com a eliminação de preconceitos e obstáculos arquitetônicos e com as leis 10.048/2000, que dá prioridade as pessoas com deficiência e a Lei $10.098 \backslash 2000$, que 'estabelece normas gerais e critérios básicos para a promoção da acessibilidade das pessoas portadores de deficiência.' (BRASIL, 2000).

O Decreto Federal no 5.296 (BRASIL, 2004) foi necessário para regulamentar as leis citadas acima e dar legitimidade aos conselhos municipais e estaduais e às organizações de portadores de deficiência. 0 decreto define, ainda, quanto às barreiras ou obstáculos que impeçam o acesso com segurança deste público.

Em 2004, foi criada a norma ABNT NBR 9050 (2004), que rege as questões de acessibilidade em edificações, mobiliários, espaços e equipamentos urbanos. A partir de então, várias cartilhas e apostilas foram criadas para dar ênfase à norma e colocar em prática suas observações. Até os dias de hoje estão em fase de adaptações, principalmente nas escolas públicas.

Segundo o Instituto Brasileiro de Geografia e Estatística (IBGE), o censo demográfico de 2010 mostra que, no Brasil, 45.606 .48 pessoas (o que representa 23,9\% da população brasileira) têm algum tipo de deficiência, sendo 18,60\% desta população com deficiência visual, 7\% com deficiência motora, 5,10\% com deficiência auditiva e 1,40\% com deficiência mental ou intelectual.

Tais observações mostram que ainda é preciso um longo trabalho a ser feito para proporcionar melhores condições de vida para estas milhões de pessoas com algum tipo de deficiência, pois elas têm direito de ir e vir como qualquer outro cidadão brasileiro. Neste sentido, foi elaborada a Norma ABNT NBR 9050 (2004), para que sejam feitas as 
mudanças necessárias nos espaços, edificações, mobiliários e equipamentos urbanos. As reformas e ampliações de edificações e de equipamentos urbanos devem seguir esta norma para serem consideradas acessíveis.

Dessa forma, a escola também deve se preparar e tornar o ambiente acessível e adaptado para poder fazer a inclusão deste aprendiz com necessidades especiais, além de estar atenta às modificações e adaptações na sua estrutura física, de forma a eliminar qualquer tipo de barreira, proporcionando um ambiente de ensino seguro e de qualidade.

Sendo assim, em seguida, apresentaremos alguns referenciais quanto a espaço, deslocamento, adaptações, dimensões e sinalizações, de acordo com a Norma ABNT NBR 9050 (2004), elaborada com base nas medidas da população brasileira. A pessoa em pé precisa de uma dimensão referente a, no mínimo, 1,20 m de espaço para locomover-se em um ambiente, levando em consideração pessoas com cão guia, bengala de rastreamento, muletas, andador e bengalas.

A utilização de cadeira de rodas impõe limites à execução de tarefas, por dificultar a aproximação aos objetos e o alcance a elementos acima e abaixo do raio de ação de uma pessoa sentada.

O espaço físico deve assegurar faixa de circulação livre de barreiras ou obstáculos, de modo a permitir deslocamento em linha reta para pessoas que necessitam de cadeira de rodas para realizar sua locomoção. As larguras mínimas necessárias são: de $0,9 \mathrm{~m}$ a $1,20 \mathrm{~m}$ de largura no piso, sendo $0,9 \mathrm{~m}$ a medida mínima da porta, facilitando a manobra da cadeira. No caso de um corredor, a largura mínima é de 0,9m, mas se o cadeirante precisar fazer a volta será complicado, pois ele terá que empurrar a cadeira de ré. Um corredor adequado é o de $1,20 \mathrm{~m}$ a 1,50m, porque permite ao cadeirante fazer um giro de $180^{\circ}$, não precisando voltar de ré. Já os corredores com metragem de 1,50m a 1,80m possibilitam a locomoção de duas cadeiras de rodas ao mesmo tempo.

A sinalização possui várias categorias, cada uma com suas devidas localizações. Apresentam-se das seguintes formas: a) sinalizações permanentes são posicionadas em áreas ou espaços já definidos de um ambiente ou edificação; b) no mobiliário devem ser usados para identificar os comandos; c) sinalização direcional, utilizada para indicar a direção de um percurso ou a distribuição espacial de uma edificação, podendo ser na forma visual de setas, figuras ou símbolos; d) sinalização de emergência, usada para indicar rota de fuga ou para alertar a existência de um perigo iminente; e) sinalização 
temporária, indicada para informações provisórias ou que podem ser alteradas periodicamente. (ABNT NBR 9050, 2004).

Todas estas sinalizações são essenciais e devem ser aplicadas e distribuídas nas edificações, no mobiliário, nos espaços. Equipamentos urbanos deverão ser sinalizados de forma visual, tátil ou sonora.

As sinalizações sonoras devem ser associadas à sinalização visual em alguns casos, segundo a Norma ABNT NBR 9050 (2004). Informações sonoras verbais podem ser digitalizadas ou sintetizadas, e devem ter as seguintes características: “a) conter apenas uma oração - uma sentença completa, com sujeito, verbo e predicado, nesta ordem; b) estar na forma ativa e não passiva; c) estar na forma imperativa." (ABNT NBR 9050, 2004).

Os símbolos internacionais de acesso são a forma mais comum de comunicação e sinalização, e sua representação de indicação de acessibilidade deverá estar nas edificações, mobiliários, espaços e equipamentos urbanos. Sua finalidade é indicar a acessibilidade aos serviços e identificar espaços onde existam elementos acessíveis ou utilizáveis por pessoas portadores de deficiência.

Para que a escola consiga cumprir estas normas de espaço, é necessário realizar modificações na estrutura física como, por exemplo, ampliação de calçadas, rampas, mudanças nos corredores. Sabe-se que a maioria das escolas não foi construída pensando em atender pessoas com deficiência.

A Norma NBR 15599 (2008) detalha requisitos, procedimentos e recursos na prestação de serviços ao público, destacando as escolas e os serviços de bibliotecas. A biblioteca de uso do público deve dispor de espaço sinalizado, profissionais capacitados para atender pessoas com deficiências, acervo com versões de obras em meio sonoro e visual e serviços de versão alternativa como programas e ampliadores de tela, além de outros dispositivos facilitadores e adaptadores para pessoas com deficiência, como resenhas gravadas em vídeos ou DVD. 0 acervo bibliográfico deve contemplar versões para os diversos sentidos de percepções.

\subsection{Acessibilidades nas Bibliotecas Escolares}

As escolas estão se adaptando às transformações, pois não podem se negar a receber alunos com necessidades especiais, entretanto, muitas não foram construídas para atender essa situação. As poucas construídas de maneira planejada, pensando nesse 
público, ainda precisam adequar-se, pois, devido às leis e normas de acessibilidade recentes, o aluno tem direito a ser tratado com igualdade.

As bibliotecas escolares, neste mesmo intuito, também precisam adaptar-se. 0 primeiro passo, é a avaliação de acessibilidade, tendo em vista o uso da biblioteca em condições de igualdade por qualquer usuário, seja ele portador de alguma deficiência ou não. Cabe à verificação da falta de planejamento das instalações e seu funcionamento: a biblioteca acessível, seja ela na planta ou que já esteja em funcionamento, tem que pensar em um acesso democrático e envolvente a todas as pessoas. Mesmo que esta não tenha nenhum aluno com necessidade especial, deverá dar condições de atendimento, pois, com a inclusão educacional, a qualquer momento as instalações terão condições de acolher estes usuários.

Assim, deverá fazer adaptações para atendimento dos usuários com necessidades especiais, observando as normas da ABNT NBR 9050 (2004) e recursos que tornem possível o acesso à informação; modernizar a biblioteca através de gerenciamento eletrônico do acervo, disponibilizar ferramentas eletrônicas proporcionando leituras em diversos suportes e incentivando a pesquisa; deverá ter no balcão de entrada sinalização que dê acesso a pessoas com necessidades especiais, para que não haja nenhum constrangimento da pessoa, pois o direito não pode ser confundido com privilégio.

A pessoa com deficiência física necessita de algumas adequações na biblioteca para que ela consiga ter acesso à informação. A biblioteca tem que estar localizada, de preferência, em terrenos planos; se não for possível, deverá ter elevadores ou rampas de acesso, em caso de prédios com mais de um andar (ABNT NBR 9050, 2004).

0 elevador deve ter dimensão mínima de 1,10m x 1,40m, porta com vão livre de, no mínimo, 0,80m, além da abertura da porta, botões com comando interno e externo com comunicador tátil e auditivo, piso com revestimento antiaderente e indicação de acessibilidade.

Todas as entradas de ambiente público ou não devem ser adequadas. Não pode haver barreiras, entraves ou obstáculos que limitem o acesso à circulação com segurança de pessoas portadoras de deficiência. As rampas são de fundamental importância para pessoas que utilizam cadeira de rodas, pois torna o ambiente edificado acessível. Elas podem ser internas ou externas. A largura mínima recomendável para rampas em rotas acessíveis é de 1,50m, sendo admissível um mínimo de 1,20 m; deverá ter inclinação longitudinal entre 6,33\% e 8,33\%; em situações excepcionais, ou a reforma poderá 
utilizar uma inclinação superior a 8,33\%, chegando até a 12,5\%, não mais que isto, inclinação transversal máxima 2\% para rampa interna e 3\% para rampa externa. Além disso, deverá ter corrimão instalado nos dois lados da rampa, bem como piso antiderrapante.

As mesas têm que ter de 0,75m a 0,85m de altura; as superfícies devem ter até, no máximo, 0,5m; suas quinas devem ser arredondadas (ABNT, NBR 9050, 2004). Devese garantir até $0,9 \mathrm{~m}$ de área livre para circulação, as estantes de livros devem ter, no mínimo, 0,90 m de largura entre si; a cada $15 \mathrm{~m}$ deverá ter um espaço que permita a manobra das cadeiras de rodas em corredores; recomenda-se a rotação de 180․

Os fichários devem ter faixa de alcance manual e parâmetros visuais. 0 balcão tem que ser acessível à pessoa com deficiência, para que ela possa se localizar. A parte frontal deve ter altura de $0,73 \mathrm{~m}$, no mínimo, sem lateral, para que o cadeirante possa aproximar-se.

Os computadores devem ter leitores de tela para alunos com deficiência visual; as mesas devem seguir as normas de altura e espaços para as manobras; e, ainda, é preciso haver contraste de cor entre as cores do piso.

Para todas estas adequações, existe um projeto do Ministério da Educação chamado Programa Escolar Acessível. Este projeto libera verbas para que as instituições se adéquem. Esse programa libera recursos financeiros para todas as escolas que têm matriculados estudantes da educação especial em classe comum do ensino regular. No Paraná, o governo estadual enviou um documento aos diretores das escolas pedindo que respondessem um questionário sobre bibliotecas escolares (SEED, 2011). 0 objetivo do levantamento é identificar a situação, em relação a acervo, catalogação, manutenção predial, acessibilidade e sistemas eletrônicos de controle do acervo e de empréstimos das bibliotecas existentes na rede estadual de ensino do Paraná.

Pelo exposto, entende-se que tem ocorrido um esforço com relação às mudanças nos ambientes e nas instalações das bibliotecas escolares, visando melhorar o atendimento nas mesmas.

\section{PROCEDIMENTOS METODOLÓGICOS}

Esta pesquisa caracteriza-se como descritiva. Segundo Gil (2010, p.28), a forma descritiva "tem como objetivo primordial a descrição das características de determinada 
população ou fenômeno ou o estabelecimento de relações entre variável". Para a coleta de dados foi utilizada a observação não participante. Nas palavras de Lakatos e Marconi (2011, p.78), "Na observação não participante, o pesquisador toma contato com a comunidade, grupo ou realidade estudada, mas sem integrar-se a ela: permanece de fora."

Destaca-se que a pesquisa teve como universo 10 colégios estaduais de Londrina, sendo 2 de cada região geográfica. Os colégios citados foram escolhidos aleatoriamente. Isto nos dá uma amostra de 10,2\% dos colégios da cidade de Londrina. A seguir, apresentamos os colégios, por região geográfica, sem que eles sejam identificados ${ }^{1}$.

\subsection{Apresentação e Discussão dos Resultados}

\subsubsection{Colégio A e B da região Central da cidade de Londrina}

Destaca-se que nos colégios A e B há uma diferença quanto à acessibilidade. 0 colégio A possui 5 alunos cadeirantes e tem acessibilidade em qualquer espaço dentro e fora dele, inclusive na biblioteca, ou seja, possui uma rota acessível tanto interna quanto externamente. Para a ABNT NBR 9050 (2004, p.4) rota acessível é o

Trajeto contínuo, desobstruído e sinalizado, que conecta os ambientes externos ou internos de espaços e edificações, e que possa ser utilizada de forma autônoma e segura por todas as pessoas, inclusive aquelas com deficiência. A rota acessível externa pode incorporar estacionamentos, calçadas rebaixadas, faixas de travessia de pedestres, rampas, etc. A rota acessível interna pode incorporar corredores, pisos, rampas, escadas, elevadores etc.

Dentre os colégios visitados, é o único com piso tátil em toda sua extensão. A biblioteca tem o seu acervo automatizado, entretanto, não possui computadores disponíveis aos usuários; assim, os alunos se utilizam do laboratório de informática para pesquisas. Na biblioteca do colégio A, o atendimento é realizado por uma professora readaptada ${ }^{2}$ e uma funcionária que tem curso técnico em biblioteconomia, o "Pró-

\footnotetext{
${ }^{1}$ Cabe ressaltar que as informações referentes aos colégios foram retiradas do site http://www.consultaescolas.pr.gov.br/consultaescolas/

2Segundo o dicionário Michaelis: Readaptação. Ato ou efeito de readaptar. Direito Investidura em função pública mais compatível com a capacidade física, intelectual ou vocacional do funcionário
} 
funcionário"3 . É importante frisar a presença do profissional bibliotecário no âmbito da biblioteca escolar, uma vez que o mesmo possui conhecimentos e habilidades que irão dinamizar tal espaço. Na visão de Cardin (2005, p.164),

O bibliotecário tem uma responsabilidade enorme, pois dependerá dele (de seus próprios valores e crenças) o resultado das ações efetuadas dentro da biblioteca: se ele considerar a educação em um sentido amplo, não limitando somente ao ensino, mas principalmente voltada a formação de hábitos e atitudes do aluno, ele não se restringirá a ser um mero técnico - administrativo a serviço da escola. Ele vai lutar pelas conquistas da igualdade de oportunidade social que possibilite a todos os estudantes o acesso ao conhecimento registrado.

No que se refere ao colégio $B$, este não possui nenhum aluno cadeirante ou com mobilidade reduzida; sua biblioteca fica no segundo andar e uma pessoa de cadeira de rodas não tem acesso a ela, pois possui dois lances de escadas. 0 acervo da biblioteca é catalogado no sistema, mas o empréstimo é realizado por meio de fichas. Destaca-se que, nesta biblioteca, os alunos têm acesso aos computadores para fazer pesquisa ou trabalho que necessite do recurso da internet. 0 atendimento é realizado por uma professora readaptada, e a outra é bibliotecária.

Referente ao espaço interno das Bibliotecas A e B, notou-se certa semelhança, uma vez que o espaço é imenso, as portas possibilitam acesso a um cadeirante, suas estantes estão nas laterais, as mesas são bem separadas em toda sua expansão, o balcão de atendimento tem acesso frontal e sua altura está dentro dos padrões de acessibilidade. Os pisos das bibliotecas são considerados acessíveis, pois são regulares e não possuem qualquer tipo de rugosidade em sua extensão que possa prejudicar uma pessoa com cadeira de rodas.

Pelo exposto, com relação aos colégios A e B da região central, foi possível constatar que alguns elementos sobre acessibilidade são contemplados nas bibliotecas de tais colégios, contudo, é necessário aprimorar outros aspectos, como, por exemplo, o acesso para a biblioteca $\mathrm{B}$.

\footnotetext{
${ }^{3}$ Segundo o MEC, "O Pró-funcionário é um programa que visa a formação dos funcionários de escola, em
} efetivo exercício, em habilitação compatível com a atividade que exerce na escola." 


\subsubsection{Colégio C e D da região Leste da cidade de Londrina}

Ao analisar os colégios C e D, notou-se uma semelhança entre eles. A biblioteca está situada no segundo andar, não possui rampa ou elevador e não há acesso para uma pessoa de cadeira de rodas. Cabe destacar, ainda, que as bibliotecas mencionadas não são informatizadas e não há acessibilidade digital. Percebe-se que para algumas bibliotecas escolares públicas a informação digital não é, de fato, importante, por vários motivos, entre eles, a falta de espaço. Mas segundo Silva (2009, p.128),

O computador tornou-se um componente indispensável para o sistema de ensino principalmente, para a biblioteca escolar, pois neste espaço o aluno pode estar em constante atividade de investigação tanto por meio dos livros, quanto por meio digital.

No colégio C (possui um cadeirante), a porta de entrada está dentro das normas de acessibilidade (ABNT NBR 9050, 2004), porém foi construída uma escada no interior da biblioteca para dar acesso ao laboratório de informática - o qual não faz parte da biblioteca - localizado no térreo, o que dificulta o acesso de um portador de necessidade especial, como, por exemplo, o cadeirante. As estantes não possuem largura mínima para uma pessoa de cadeira de rodas, as mesas não são adequadas e não há espaço entre si para circulação; o ambiente é extremamente apertado e sem ventilação; o balcão de atendimento tem a altura acessível, mas sem entrada frontal para cadeirante. Para que o aluno cadeirante possa fazer o uso do acervo, ele necessita da ajuda de uma colega de turma. Infelizmente, é possível perceber que a biblioteca do colégio C não atende aos requisitos mínimos para promover o acesso à informação, o que faz com que a mesma se torne um entrave à questão do conhecimento no âmbito escolar. Para Marcolino e Castro Filho (2014, p.8),

Na educação inclusiva, o aluno deficiente fará uso da biblioteca escolar assim como os demais. Mesmo com todas as suas dificuldades, ele também necessitará ter contato com os livros e demais materiais de apoio pedagógico. Inserir uma pessoa com deficiência nas escolas regulares junto com alunos sem deficiência não significa integrá-la. Integrar um deficiente significa colocá-lo nas práticas escolares de forma ativa e deixar de lado o pensamento de que ele é um ser unicamente passivo. 
Como foi visto anteriormente há muitas leis e decretos para que haja a inclusão das pessoas com necessidades especiais nas escolas, mas pode-se observar que isto ainda não acontece integralmente dentro dos colégios pesquisados. Outro fato preocupante na biblioteca $C$ é que os alunos não a utilizam para fazer pesquisa; apenas trocam de livros em dias determinados. Neste contexto, pode-se notar a falta de incentivo para a utilização da biblioteca no processo educativo. Garcia (1989, p.11) afirma que:

\footnotetext{
Entre os diversos meios educativos, encontra-se a biblioteca - recurso indispensável para o desenvolvimento do processo ensino-aprendizagem e formação do educando. Pode-se afirmar que uma escola sem biblioteca é uma instituição incompleta, e uma biblioteca não orientada para um trabalho escolar dinâmico torna-se um instrumento estático e improdutivo dentro desse contexto.
}

A partir disso, pode-se observar que neste colégio falta entender que a biblioteca faz parte da educação dos alunos. 0 atendimento é feito por quatro professores readaptados e uma bibliotecária.

No colégio D, a porta de entrada não possibilita o acesso a uma pessoa cadeirante, as estantes estão fora das normas de acessibilidade, há apenas uma pequena mesa com duas cadeiras que não permite a aproximação de uma pessoa de cadeira de rodas, o balcão tem altura estabelecida pelas normas, mas não do acesso frontal, o piso não é antiderrapante, o sujeito que atende é um professor readaptado.

Foi possível observar que, infelizmente, as bibliotecas situadas nos colégios mencionados na região leste não contemplam o mínimo de acessibilidade aos usuários portadores de alguma necessidade física e não incentivam o uso da biblioteca pelos outros alunos.

\subsubsection{Colégio E e F da região Oeste da cidade de Londrina}

Os dois colégios foram construídos em forma horizontal, sem escadas. As bibliotecas são bem localizadas dentro do ambiente escolar, as portas estão dentro dos padrões, a circulação de entrada é contínua sem obstáculos, os pisos não são antiderrapante, os balcões de atendimento estão na altura adequada, não há profundidade livre na parte frontal para atender um cadeirante. 0 colégio $\mathrm{F}$ possui computadores disponíveis aos usuários na biblioteca, enquanto o colégio E não possui. 
A biblioteca do colégio E fica o maior tempo trancada por falta de funcionários para atendimento. Ela conta com duas professoras readaptadas: uma está para se aposentar e a outra tem síndrome do pânico, o que a impede de realizar o atendimento ao usuário, apesar de fazer todo o serviço interno da biblioteca. Cabe destacar que a biblioteca escolar deve sempre estar aberta aos alunos, uma vez que, de acordo com Bicheri e Almeida Júnior (2013, p.43),

A simples existência de uma biblioteca escolar, bem localizada, de bom tamanho, bem decorado, com um grande acervo atualizado não é suficiente para atender as necessidades da comunidade escolar e contribuir para a qualidade do ensino e formação do aluno.

A partir disso, entende-se que nesta escola o gestor e a comunidade escolar ainda não perceberam com clareza a importância da biblioteca escolar para a formação dos alunos.

No colégio F, a biblioteca fica aberta no período integral, os alunos a utilizam intensamente, seja para pesquisa ou empréstimo de livros. Além disso, há dois terminais de computadores com internet disponíveis para os estudantes e os profissionais que realizam o atendimento são, respectivamente, um administrativo e um professor readaptado. Para Corte (2011, p.11),

\begin{abstract}
A biblioteca escolar deve atuar como órgão auxiliar e complementar da escola, facilitando aos alunos o livre acesso aos livros - o mundo fantástico do saber, das descobertas, dos sonhos, do imaginário conto de fadas ao mundo do assombrado. Bem como a orientação clara e precisa para o estudo, para a solução de problemas e dos deveres de classe, ou, ainda incrementar as pesquisas referenciando-as, utilizando mais de um livro, sintetizando, criticando e fundamentalmente como apoio informacional ao pessoal docente.
\end{abstract}

Neste caso, a biblioteca escolar do colégio F está cumprindo seu papel dentro do ambiente escolar, fomentando o acesso à informação e propiciando o desenvolvimento dos conhecimentos na escola.

Em síntese, foi observado que a biblioteca E precisa urgentemente que a direção da escola tome providências quanto ao atendimento. Em contrapartida, a biblioteca $\mathrm{F}$ deve reorganizar o espaço para dar mais acessibilidade ao ambiente e aos sujeitos que a frequentam. 


\subsubsection{Colégio G e $\mathrm{H}$ da região Norte da cidade de Londrina}

A biblioteca do colégio G está localizada logo na entrada prédio da instituição. A porta está fora dos $90 \mathrm{~cm}$ estipulados pela norma (ABNT 9050, 2004), mas a atendente da biblioteca informou que a porta será trocada, pois já está previsto no projeto de reforma da escola. Destaca-se que a biblioteca não tem rampa de acesso, a circulação é contínua e não tem obstáculos na entrada, entretanto, não há sinalização tátil. 0 corredor apresenta largura mínima de $90 \mathrm{~cm}$ de largura, o piso é regular, mas não é antiderrapante. Por outro lado, o balcão está em rota acessível, porém, sua longitude não apresenta altura de no máximo $90 \mathrm{~cm}$, o que dificulta o contato visual do bibliotecário e o usuário cadeirante, por exemplo, além de não haver profundidade necessária para aproximação frontal de uma cadeira de rodas.

Na referida biblioteca, as mesas de leitura estão dentro das normas, são bem distribuídas dentro do ambiente, os mobiliários estão distribuídos de forma que favorece o contato visual com toda a biblioteca. Junto à biblioteca está instalado o laboratório de informática, mas não é permitido fazer pesquisa sem a presença de um professor. 0 atendimento é feito por duas funcionárias do setor administrativo. Um dado a ser apontado é que tais funcionárias informaram que os alunos não têm tanto interesse pela biblioteca. Neste contexto, é importante o papel do bibliotecário, assim como do corpo docente, em motivar os alunos para o uso da biblioteca. Uma das formas de fazê-lo é, segundo Silva (2002), entre outras condições, enraizar o gosto pela leitura nos alunos, tendo em conta os seus interesses, as suas necessidades, proporcionando-lhes um atendimento que os oriente, os esclareça e os motive.

Quanto ao Colégio H (4 alunos cadeirantes), sua rota até a biblioteca tem escadas e rampas nas laterais da escola, estas rampas não têm corrimão e a largura é de 1,10m, o que está fora da largura mínima exigida pelas normas da ABNT NBR 9050, ou seja, 1,20m. 0 piso é regular, mas não é antiderrapante. 0 balcão está em rota acessível, porém, assim como no colégio $\mathrm{G}$ da região norte, sua longitude não apresenta altura de no máximo 90 $\mathrm{cm}$, dificultando o contato visual entre bibliotecário e usuário, além de não haver profundidade necessária para aproximação frontal de uma cadeira de rodas. As mesas de leitura estão dentro das normas (ABNT9050/2004), mas não são bem distribuídas dentro do ambiente. Já a disponibilização dos mobiliários favorece o contato visual com toda biblioteca. 
A biblioteca possui três computadores com acesso à internet para uso dos alunos em pesquisa. Foi dividida com a sala de aula para o "Projeto Mais Educação"4. Em virtude da redução do espaço da biblioteca, os computadores destinados aos alunos especiais foram transferidos para o laboratório de informática. Atualmente o atendimento é feito por uma funcionária do quadro administrativo, a qual informou que os alunos frequentam bastante a biblioteca para realizarem trabalhos, pesquisa e empréstimo de livros.

Cabe mencionar que, durante a observação, a pesquisadora pôde constatar uma situação na qual um usuário necessitou de informações para realização de uma pesquisa escolar, sem nenhuma instrução da professora. A responsável pela biblioteca tomou iniciativa de indicar o material bibliográfico para o aluno, contribuindo para que o mesmo desenvolvesse a pesquisa. Desta forma, foi possível perceber que esta pequena ação por parte da funcionária mencionada é uma forma de incentivar o aluno à pesquisa, assim como contribuir para que o mesmo desenvolva um interesse pelo uso da biblioteca, ao contrário da funcionária do colégio $\mathrm{A}$, da região norte, que relatou não haver interesse da parte dos alunos pela biblioteca, sem, ao menos, propor uma solução para tal situação exposta.

Durante a pesquisa, foi possível observar que depende quase que exclusivamente das pessoas que trabalham nas bibliotecas para que elas tenham boa frequência, que os alunos se sintam acolhidos e incentivados a fazer pesquisa, leitura ou, simplesmente, dar aquela passadinha para dar um "bom dia” ou "boa tarde" aos funcionários.

\subsubsection{Colégio I e J da região sul da cidade de Londrina}

A biblioteca do colégio I está próxima da entrada do colégio, a porta está dentro dos $90 \mathrm{~cm}$ estipulados pela norma (ABNT NBR 9050, 2004). Destaca-se que a biblioteca não tem rampa de acesso, a circulação é contínua e não há obstáculos na entrada, contudo, não há sinalização tátil. 0 corredor apresenta largura mínima de $90 \mathrm{~cm}$ de largura, o piso é regular, mas não é antiderrapante.

Nota-se que o balcão está em rota acessível, porém, sua longitude não apresenta altura de, no máximo, $90 \mathrm{~cm}$, o que dificulta o contato visual do bibliotecário e o usuário

${ }^{4}$ Projeto inserido no Programa Mais Educação que, segundo o MEC, é uma estratégia do governo federal para a promoção da educação integral no Brasil contemporâneo. 
cadeirante, por exemplo, além de não haver profundidade necessária para aproximação frontal de uma cadeira de rodas. As mesas de leitura estão dentro das normas, são bem distribuídas, mas o ambiente é apertado para a circulação de uma cadeira de rodas. A biblioteca possui dois computadores com acesso à internet para uso dos alunos em pesquisa.

Além disso, a biblioteca utiliza o sistema Biblivre para catalogar seu acervo e atende os usuários para impressão de trabalho e cópias. São três funcionários que realizam o atendimento: dois trabalham nos períodos da manhã e da tarde, e o outro, no da noite; os três são administrativos, mas duas são formadas em biblioteconomia com especialização em biblioteca escolar.

Cabe destacar que os funcionários administrativos que atuam na biblioteca, tendo em vista a lei 12.244 - que dispõe que todas as escolas devem ter biblioteca com bibliotecário -, estão se especializando não somente para se adequarem ao que a legislação determina, mas também pela possibilidade de novas oportunidades no contexto da escola. Isso contribuirá para o atendimento e prestação de serviços aos usuários da biblioteca, uma vez que a mesma contará com o trabalho do bibliotecário. Como afirma Silva (1999, p.79), a tarefa de orientar o aluno na utilização da biblioteca e, principalmente, o de "Despertar nele o gosto e o hábito de leitura são as atribuições mais reveladoras da natureza educativa do trabalho biblioteconômico na escola". Assim, o bibliotecário participa diretamente de todo os acontecimentos que circundam o ambiente escolar.

Na biblioteca do colégio I, foi possível observar que existe uma boa frequência dos alunos: está sempre cheia, seja para imprimir trabalhos, para retirar livros, para a busca de material como dicionários ou para fazer pesquisa, pois a biblioteca atende em horário inverso os alunos que precisam fazer trabalho. 0 aluno cadeirante, quando precisa, utiliza a biblioteca normalmente e, caso precise usar o computador, ele tem um notebook à sua disposição.

O colégio J possui escada e rampas em sua entrada, mas não no acesso à biblioteca escolar. Destaca-se que a biblioteca está localizada próximo da entrada dos alunos, em frente à secretaria. $\mathrm{O}$ espaço é imenso, as portas possibilitam acesso a um cadeirante e suas estantes estão todas nas laterais, as mesas bem separadas ao longo de sua expansão, o balcão de atendimento tem acesso frontal e sua altura está dentro dos padrões de acessibilidade. 
Nesta biblioteca, os pisos são considerados acessíveis, pois são regulares e não possuem qualquer tipo de rugosidade em sua extensão que possa prejudicar uma pessoa com cadeira de rodas. A escola não possui aluno cadeirante, entretanto, é importante frisar que a funcionária que atendeu a responsável por esta pesquisa informou que havia um aluno, mas este desistiu de estudar devido à dificuldade de chegar até a escola.

A biblioteca tem um funcionário administrativo que 'faz o que pode', pois dentro da escola ele tem outras funções, inclusive, em uma parte do dia, ele acompanha os alunos do Projeto Mais Educação, já citado nesta pesquisa. Há um sistema de catalogação livre na biblioteca e não tem computadores para uso dos usuários, assim, quando o aluno necessita fazer alguma pesquisa, utiliza o laboratório de informática ao lado da biblioteca.

Percebe-se que a biblioteca da escola I precisa de melhor organização em seu espaço para que os alunos com deficiência possam ter segurança para adentrar sem constranger ou incomodar as outras pessoas que ali estão, uma vez que, da forma como está disposta, é necessário que o mesmo empurre algumas mesas para poder entrar. A biblioteca J tem condições de atender qualquer eventual usuário com deficiência, mas, devido ao lugar que a escola foi construída, o acesso é dificultado em virtude da existência de uma inclinação

Em síntese, esta é a situação observada nas bibliotecas pesquisadas com relação às questões que envolvem a acessibilidade nestes ambientes. A seguir, serão apresentadas as considerações finais acerca da referente pesquisa.

\section{CONSIDERAÇÕES FINAIS}

Este trabalho teve como objetivo observar como está a acessibilidade das bibliotecas escolares estaduais de Londrina. Das bibliotecas escolares visitadas, foi observado que apenas a biblioteca J, construída recentemente, está realmente preparada na questão de acessibilidade, mas, mesmo assim, não está 100\% dentro das normas da ABNT NBR 9050 para o atendimento satisfatório dos usuários com necessidades especiais. No que se refere às outras bibliotecas pesquisadas, quando da presença de aluno cadeirante, propiciam uma maneira de atender, mesmo que não possibilitem diretamente uma inclusão.

Foi possível constatar que há um longo trabalho a ser feito, tanto pelas instâncias governamentais quanto pelos diretores gestores das escolas públicas, pois, através das 
observações, percebeu-se que alguns não têm preocupação com este ambiente interno da escola, ou não há pessoas qualificadas para trabalhar em biblioteca escolar.

A pesquisa apontou a necessidade de profissionais com dinamismo, próatividade e empenho no serviço no cotidiano das bibliotecas para que alunos, professores e toda a comunidade escolar tenham prazer em ir até a biblioteca para lerem ou realizarem uma pesquisa. Cabe destacar que apenas três bibliotecas têm bibliotecário formado e uma com curso técnico de biblioteca, as outras contam com funcionários administrativos ou professores readaptados, o que reflete a carência de bibliotecários atuando em biblioteca escolar na cidade de Londrina.

Com relação às leis de acessibilidade para atendimento nas bibliotecas, apenas dois funcionários disseram ter este conhecimento. Infelizmente, grande parte nunca ouviu falar sobre uma lei específica.

Foi verificado que as edificações escolares não foram construídas para atender as pessoas com necessidade especiais, o que demonstra a necessidade de mudanças na infraestrutura visando à acessibilidade, como já ocorre em algumas bibliotecas escolares da rede privada. É importante frisar que nas escolas da rede privada, se não houver acessibilidade, não é concedida habilitação para seu funcionamento.

Vários problemas foram constatados pela autora desta pesquisa, durante as visitas às escolas. Constatou-se, por exemplo, que algumas bibliotecas estão localizadas no segundo andar dos prédios, sem possibilidade de acesso aos alunos cadeirantes.

Por fim, foi observado que, para que as pessoas com necessidades especiais tenham acesso às bibliotecas escolares e seu direito de ir e vir seja cumprido de fato, será necessário que todos dentro no colégio considerem a biblioteca como espaço educacional, didático, pedagógico e cultural, pois todos, sem distinção, têm direito de usufruir deste espaço. Assim, destaca-se que o profissional bibliotecário deve voltar seu olhar para a questão da acessibilidade em bibliotecas, indo além de seu trabalho técnico, ou seja, voltando sua atenção para os usuários de forma macro.

\section{REFERÊNCIAS}

ADAPTANDO o seu imóvel. Rampas e escadas. 2014. Disponível em:

<http://adaptandoseuimovel.wordpress.com/rampas/>. Acesso em: 15 maio 2014.

ASSOCIAÇÃO Brasileira de Normas Técnicas. ABNT NBR 15599: Acessibilidade: Comunicação na prestação de serviço. Rio de Janeiro, 2008.7 - 11p. 
ABNT NBR 9050: Acessibilidade a edificações, mobiliários, espaço e equipamentos urbanos. Rio de Janeiro, 2004. 97p.

BICHERI, Ana Lúcia Antunes de Oliveira; ALMEIDA JUNIOR, Osvaldo Francisco. Bibliotecário escolar: um mediador de leitura. Biblioteca Escolar em Revista, Ribeirão Preto, v.2, p. 41-54, 2013. Disponível em: <http://revistas.ffclrp.usp.br/BEREV/article/viewFile /257/pdf>. Acesso em: 15 Maio 2014.

BRASIL. Lei n.o 12.244, de 24 de maio de 2010. Disponível em:< http://www.planalto.gov.br/ccivil_03/_Ato2007-2010/2010/Lei/L12244.htm>. Acesso em: 21 jun.2013.

Ministério da Educação. Programa Nacional Biblioteca da Escola (PNBE): leitura e biblioteca nas escolas públicas brasileiras. Brasília, D.F: Ministério da Educação, 2008. 130 p.

Decreto n. ${ }^{-2.296}$, de 2 de dezembro de 2004. Disponível em:

<http://www.planalto.gov.br/ccivil_03/_ato2004-2006/2004/decreto/d5296.htm>. Acesso em: 28 abr. 2013.

Lei n.o 10.098, de 19 de dezembro de 2000. Disponível em: < http://www.planalto.gov.br/ccivil_03/leis/l10098.htm>. Acesso em: 03 Agosto. 2014.

Ministério da Educação. Programa Nacional Biblioteca da escola (PNBE): leitura e bibliotecas nas escolas públicas brasileiras. Brasília: Ministério da educação, 2000.

Constituição República Federativa do Brasil de 1988. Brasília, DF: Senado Federal. Disponível em: <http://www.planalto.gov.br/ccivil_03/constituicao/ constituicaocompilado.htm>. Acesso em 15 Out.2013.

Lei 7.405, de 12 de novembro de 1985. Brasília, 1985.

Ministério da Educação. Curso Técnico de Formação para os Funcionários da Educação. Disponível em:

<Portal.mec.gov.br/index.php/?option=com_content\&view=article\&id=12365>.Acesso em:26 out.2014.

. Ministério da Educação. Programa mais Educação: passo a passo. Disponível em: <http://portal.mec.gov.br/dmdocuments/passoapasso_maiseducacao.pdf >.Acesso em:26 out.2014.

CORTE, Adelaide Ramos; BANDEIRA, Suelena Pinto. Biblioteca escolar. Brasília: Briquet de Lemos, 2011.

GARCIA, Edson Gabriel. Biblioteca Escolar: Estrutura e Funcionamento. São Paulo: Loyola, 1989.

GIL, Antônio Carlos. Métodos e técnicas de pesquisa social. 6.ed. São Paulo: Atlas,2010.

MARCOLINO, Maria Antonieta Ribeiro; CASTRO FILHO, Claudio Marcondes de. O bibliotecário na biblioteca escolar e os usuários especiais: o desafio da inclusão .Revista RBBD, v.10,p.13 2014. Disponível em: http://rbbd.febab.org.br/rbbd/article/view/331/307 Acesso em :17 out.2014 
MARCONI, Marina de Andrade; LAKATOS, Eva Maria. Técnicas de pesquisa. 7. ed. São Paulo: Atlas, 2011.

MELO, Amanda Meincke; PUPO, Deise Tallarico. A educação Especial na Perspectiva da Inclusão Escolar: livro acessível e informática. Brasília: Ministério da Educação, 2010.

PARANÁ. Secretaria de Estado da Educação.[SEED] Questionário sobre biblioteca escolar. Disponível em: <http://www.educacao.pr.gov.br>. Acesso em 7 de maio 2014.

. Secretaria de Estado da Educação[SEED]. Dia a dia educação. Disponível em:< http://www.educadores.diaadia.pr.gov.br/index. php>. Acesso em 20 de Out. 2014.

. Secretaria de Estado da Educação.[SEED] Educação profissionalizante. Disponível em: <http://www.educadores.diaadia.pr.gov.br/modules/conteudo/conteudo.php?conteudo=611>. Acesso em 20 de Out. 2014.

READAPTAÇÃO. In: Michaelis: dicionário Online. Disponível em: <http://michaelis.uol.com.br>. Acesso em: 20 out. 2014

SILVA, Lino Moreira. Bibliotecas escolares e construção do sucesso educativo. Braga: Instituto de Educação e Psicologia, Universidade do Minho, 2002.

SILVA, Rovilson José da; BORTOLIN, Sueli. Reflexões sobre a leitura e a biblioteca escolar. In: SILVA, Rovilson José da; BORTOLIN, Sueli. Fazeres cotidianos na biblioteca escolar. São Paulo: Polis, 2006.

SILVA, Waldeck Carneiro da. Miséria da biblioteca escolar. 2.ed. São Paulo: Cortez, 1999, 119p. 